\title{
Multidisipliner yaklaşımla yeni gülüş tasarımı: Olgu sunumu
}

\author{
Ayşe Koçak Büyükdere ${ }^{\alpha}$, Esra Güzeldemir Akçakanat ${ }^{\beta}$
}

Selcuk Dent J, 2017; 4: 23-27

Başvuru Tarihi: 27 Ekim 2016 Yayına Kabul Tarihi: 10 Nisan 2017

\author{
Öz \\ Multidisipliner yaklaşımla yeni gülüş tasarımı: Olgu sunumu
}

Diş hekimliğinde estetik başarı doğru tanı, tedavi planı, klinik ve laboratuvar uygulamalarına dayanmaktadır.

Üst dişlerin görünürlüğü yaş ile beraber azalmaktadır. Ön dişlerin açıklığı ile de üst ön diş görünürlüğü çok daha azalmaktadır. Bu olgu raporunda, ön grup açık kapanış şikayeti olan 37 yaşında kadın hasta anlatılmaktadır. Uzun süreceği düşünülen ortodontik tedavi yerine protetik yaklaşımla gülüş tasarımı planlandı. Üst ön kesici dişlerin ve yan kesici dişlerin görünürlüğü altın orana göre dizayn edilerek estetik gülüş sağlandı. Üst çeneye uygulanan üç porselen vener ile hem estetik gülüş sağlandı hem de konservatif tedavi uygulandı.

Üç yıllık takip sonucunda yumuşak doku ile dişler arasındaki uyumun klinik olarak ideal olduğu gözlendi.

\section{ANAHTAR KELIMELER}

Açık kapanış, diş kaplamaları, gingivoplasti

Çene kaslarındaki dengesiz aktiviteler, normal olmayan dil basıncı, zayıf ısırma kuvvetleri ön grup dişlerde açık kapanışa sebep olduğu ve ağız açıklığının da dil emmeyi tetiklediği belirtilmiştir. ${ }^{1}$ Sentrik okluzyonda ön dişlerde temasın olmaması, açık kapanışın klinik bulgularından biridir ve oklüzal stabiliteyi azalttığı bildirilmektedir. ${ }^{1-3}$

Erken yaşta belirlenen dil itim kaynaklı sorunlarda, miyofonksiyonel terapi veya apareyler ile dilin yeniden pozisyonlandırılması sağlanıp tedavi edilmektedir. ${ }^{3,4}$ İleri yaşta açık kapanış olgularının tedavisinde ortodontik tedavi daha uzun olmakta ve geri dönüşüm görülebilmektedir. ${ }^{5}$

Ağız açıklığı gibi çocukluk çağından beri olan fiziksel özellik kişinin kendi için sıradan bir olay olsa da zaman içinde çevresini değiştirmesiyle beraber

\section{ABSTRACT}

New esthetict smile with multdisiplinier aspect: A case report

The esthetic success of a dental treatment depends on the correct diagnosis, treatment plan and clinical and laboratory procedures.

Visibility of the upper teeth decrease with ages. The anterior open bite reduces the visibility of the upper teeth. In this case report, 37-year-old female with anterior open mouth sendrome is described. Long treatment plan for orthodontict treatment, prosthetic treatment were planned for esthetic smile. Esthetic smile is designed according to the golden ratio of the central and lateral incisors proportions. With three porcelain veneers for the upper jaw were esthetic smile and conservative treatment were applied.

Soft tissue and the teeth harmony were ideal for the clinically ideal for the three year follow up.

\section{KEYWORDS}

Open-bite, dental veneers, gingivoplasty

algıda değişikliğine sebep olabilmektedir, bu da kişilerin estetik beklentilerini etkilemektedir. ${ }^{6}$ Estetik gülüşteki uyum ve simetri, dişlerin şekilleri, boyutları, renkleri ve dişetlerinin görünürlüğünün sağlanması ile elde edilmektedir. ${ }^{7}$

Ön dişlerdeki renklenme, form bozukluğu, çapraşıklık, kırılmalar gibi estetik sorunların koruyucu diş hekimliğiyle, diş dokusundan, çok daha az madde kaldırılarak seramik lamina venerler ile estetik tedaviler yapılabilmektedir. ${ }^{8-11}$

Protetik tedaviye başlamadan önce dudak desteği, diş ve dişeti arasındaki uyum, dişlerin pozisyonları, gülme ve konuşma sırasında dişlerin görünürlüğü de değerlendirilmektedir. ${ }^{12,13}$ Değerlendirme sonucunda restorasyonun tamamlandığındaki durumunu anlamak için model üzerinde veya ağız içinde

\footnotetext{
${ }^{\alpha}$ Kocaeli Üniversitesi Diş Hekimliği Fakültesi Protetik Diş Tedavisi Anabilim Dalı, Kocaeli

$\beta$ Kocaeli Üniversitesi Diş Hekimliği Fakültesi Periodontoloji Anabilim Dalı, Kocaeli
} 
çalışma yapılmaktadır. ${ }^{14}$ Bunun sonucu dişetinde düzenleme yapılıp yapılmamasını göstermektedir.

Periodontal cerrahiden sonra, dişlerin rengini ve morfolojisini düzenlemek için, estetik ve konservatif tedavi alternatiflerinden olan porselen venerler kullanılmaktadır. Venerler, hem biyouyumlu hem de estetik olmalarından dolayı ön grup restorasyonlar da tercih edilmektedir. ${ }^{15-19}$

Bu olgu sunumunda basit ön açık kapanışı olan bir kadın hastada, estetik ihtiyacı karşılamak için planlanan tedavi yaklaşımı ve tedavinin üç yıllık takip sonuçları anlatılmaktadır.

\section{OLGU SUNUMU}

Ön bölge açık kapanışı olan 37 yaşındaki kadın hasta Kocaeli Üniversitesi Diş Hekimliği Fakültesi Protetik Diş Tedavisi Anabilim Dalı'na başvurdu. Hastanın yutkunma sırasında ön açık bölgeye dilini yerleştirdiği belirlendi. Dilin konumundan kaynaklandığı düşünülen açık kapanışın düzeltilmesi hastadan alınan onam ile planlandı.

Hastanın klinik muayenesinde, hastaya profilden bakıldığında ön dişlerinin ters eğim yaptığı ve alt ve üst dişler arasında açıklık olduğu gözlendi (Resim 1). Hasta, konuşurken ve gülerken ortaya çıkan bu durumdan memnun değildi. Gülme sırasında dudak uyumuna bakıldığında, ön grup dişlerle alt dudak arasında paralelliğin sağlanmadığı (Resim 2) ve dişetlerinin simetrik olmadığı belirlendi.

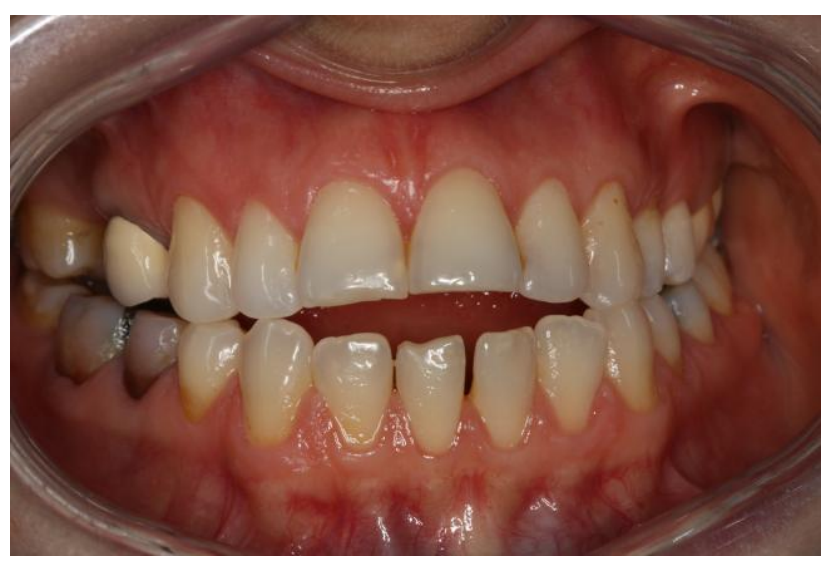

Resim 1.

Ağız içi görüntüsü

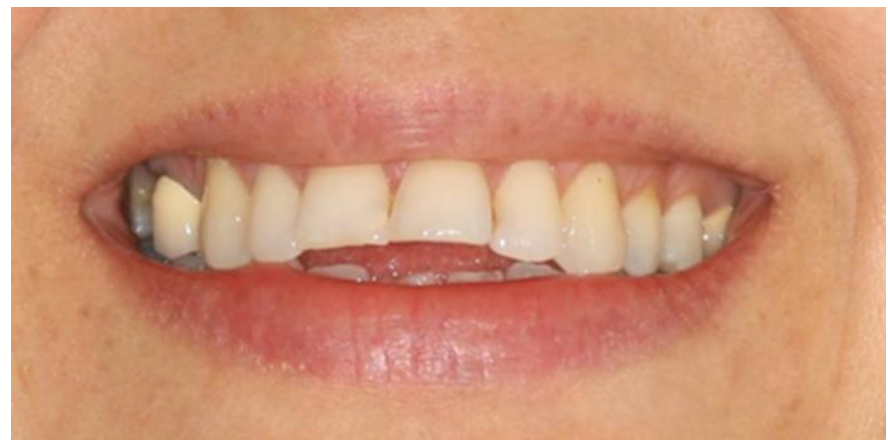

Resim 2.

Üst dişlerin alt dudak ile olan paralelliğinin incelenmesi

Açık kapanışı kapatmak için düşünülen ortodontik tedavinin uzun süreceğinden ve dişlerin eski pozisyonun dönme ihtimalinden dolayı protetik tedavi seçildi. Hastadan teşhis modeli elde edildi, model üzerinde, mum modelaj yapılarak ön bölge dişlerin boy-en uyumu, estetik gülüş için kaç dişin restore edilmesi gerektiği ve restorasyonların son hali belirlendi.

Gülme hattındaki dişlerin dişetlerindeki simetriyi sağlamak için şekillendirilme yapıldı. Santral dişler ve kanin dişlerin dişeti seviyelerinin eşitlenip, lateral dişlerin yaklaşık bir milimetre daha koronalde olması cerrahi öncesi planlandı. Belirlenen seviyede kron boyu uzatma ve dişeti düzenlenmesi yapıldı (Resim 3).

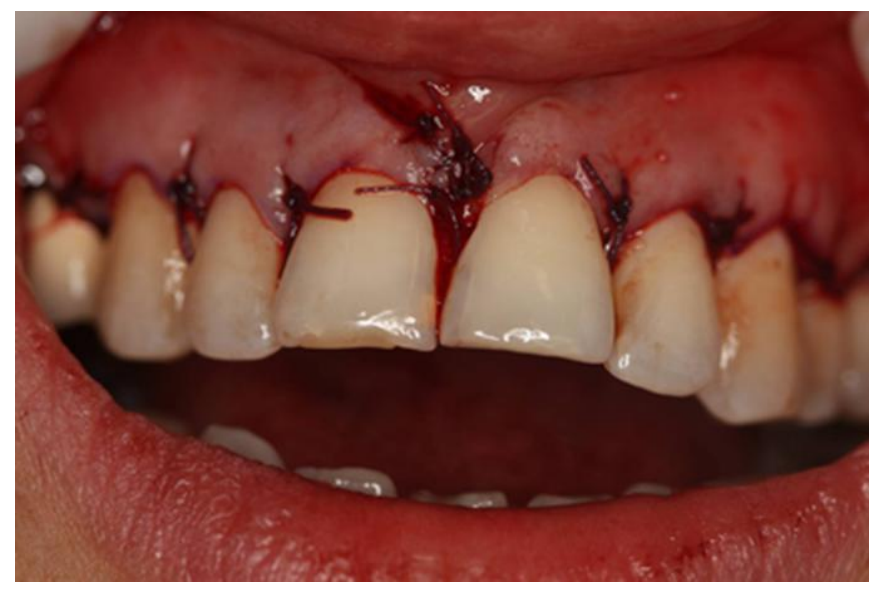

Resim 3.

Dişeti operasyonu sonrası 
Dişeti iyileşmesini takiben hastanın tek ve açık diş rengi istemesinden dolayı iki seansta, klinikte diş beyazlatma (Beaming White Türkiye) uygulandı. İkinci beyazlatma seansından sonra diş renginde bütünlük sağlandı. Üst çene sağ santral, sol santral ve sol lateral dişe konservatif bir tedavi seçeneği olan, porselen vener yapıldı. Kesim yapılan dişlerde teknisyenin dişlerin genişliklerini daha rahat ayarlayabilmesi için mezial ve distal sınır kesimleri palatinal tarafa taşındı. Insizal kenarda ise yeterli kalınlık sağlayıp dişlerin boylarını uzatabilmek için kesici kenarda düz bir kesim ile yapılacak malzemenin dayanıklıı̆ını arttırmak amaçlandı (Resim 4). Lityum disilikat cam seramiklerle presleme tekniği ile porselen venerler yapıldı (Resim 5). İstirahat durumunda üst dişlerin görünürlüğü sağlandı. Vener restorasyonlarla hastada protroziv harekette insizal rehberlik elde edildi. Ön açık kapanışın uyumlu bir şekilde kapanması ve dişlerin konturlarının düzenlenmesi için alt çene ön bölgedeki dişlere kompozit vener restorasyonlar yapıldı. İleri ki dönemde gerekli görüldüğünde kompozit vener restorasyonların porselen restorasyonlarla değiştirilme imkanı belirtildi (Resim 6).

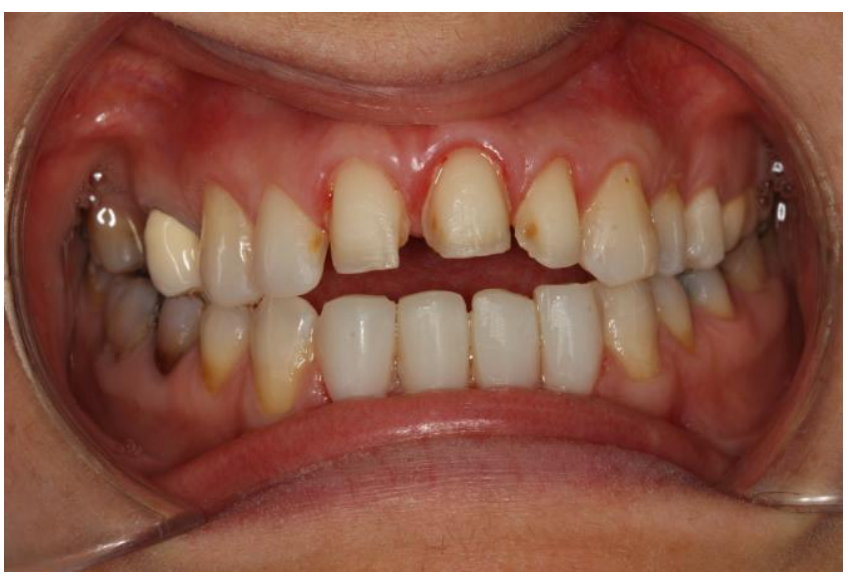

Resim 4.

Diş kesimi

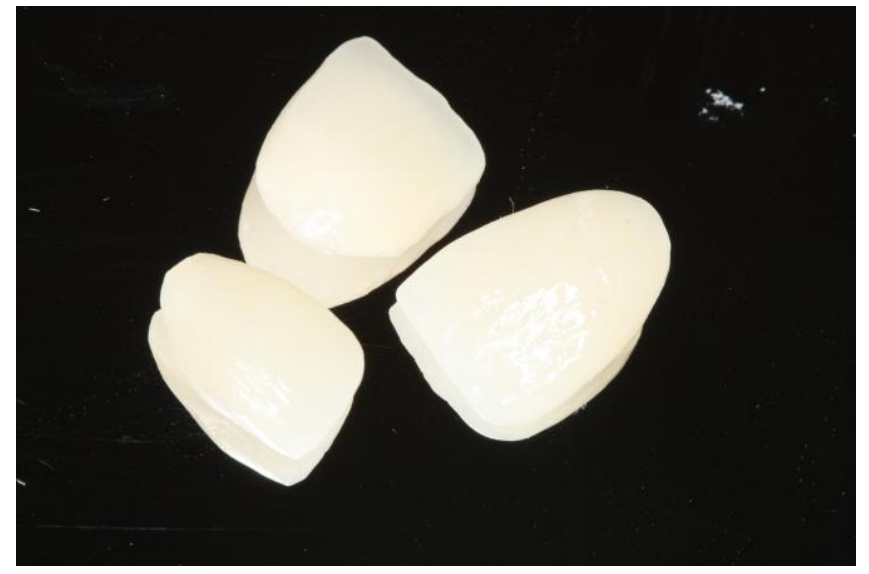

Resim 5.

Lityum disilikat restorasyonlar

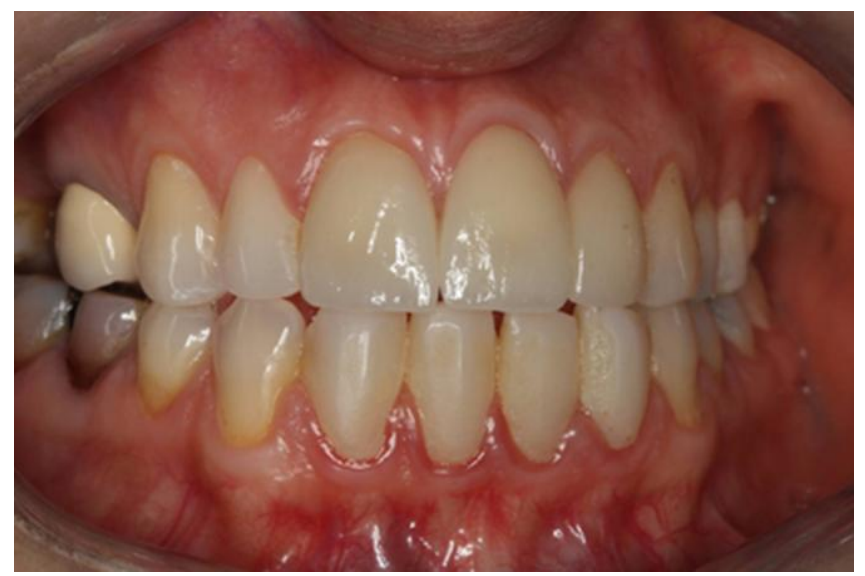

Resim 6.

Restorasyon sonrası ağız içi görüntüsü

Hastanın 3 yıllık klinik takibi sonucu, modifiye USPHS kriterlerine göre değerlendirildiğinde porselen venerlerin anatomik formlarının, renk uyumlarının ve marjinal kenar uyumlarının klinik olarak kabul edilir olduğu belirlendi ${ }^{20}$ (Resim 7).

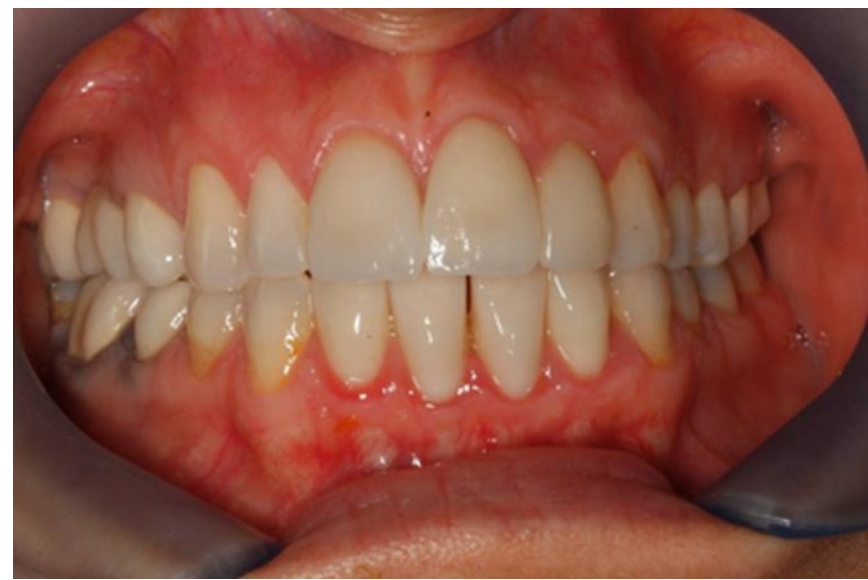

Resim 7.

3 yıl sonraki ağız içi durumu 


\section{TARTIŞMA}

Açık kapanış şikayeti iskeletsel veya diş kaynaklı olabilir. Diş kaynaklı açık kapanış, protetik uygulamamalarla tedavi edilebilir. ${ }^{4} \mathrm{Bu}$ olguda dişlerin gelişimi ve boyutu normal olup ön dişler arasında açıklık izlendi. Bu tip vakalarda süt dentisyon veya karmaşık dişlenme döneminde alışkanlık değiştirme yoluna gidilebilir veya alışkanlık önleyici apareyler takılarak tedavi yapılabilir. ${ }^{4}$ $\mathrm{Bu}$ olgu sunumunda anlatılan hastanın ön açık kapanışı hastanın erişkin döneminde izlendi. Basit ön açıklık olarak tarif edilebilir. Tedavi seçeneği olarak ortodontik tedavi veya restorasyonla ön açıklık kapatılabilir. Bu vakada protetik uygulama kullanıldı.

Restorasyonların estetiği, çevre dokularla olan uyum ile yakından ilişkilidir. Yumuşak dokularda yapılacak değişiklikler ve düzenlemeler restorasyonların fonksiyon ve estetik özellikleri açısından önemlidir. ${ }^{12}$

Bu vakada dişlerin dişeti seviyelerini ayarlamak için kron boyu uzatma yapıldı. Santral dişlerin dişeti sınırı kanin dişlerin dişeti sınırları ile eşitlenip lateral dişlerin dişeti seviyeleri koronale doğru çekilerek dişeti uyumu yakalanmaya çalışıldı.

Ön grup dişlerde rutinde tercih edilen beyazlatma işlemi ile hastaların diş renkleri ile oynamak mümkündür. Ofis veya evde uygulanan yöntemlerin süre bazında eşit zamanda uygulandığında istenilen başarı sağladığı bildirilmiştir. ${ }^{18} \mathrm{Bu}$ vakada ofiste beyazlatma yöntemi ile beyazlatma işleminin hekimin kontrolünde olması sağlandı.

Vener kesimlerinde labial yüzeylerde chamfer kesim restorasyonun adaptasyonu için daha çok tercih edilir. Proksimal yüzeylerde teknisyenin daha rahat çalışıp düzenlemeler yapabilmesi için palatinal yüzeye doğru incelen ama yok olmayan kesim yapılmalıdır. ${ }^{11} \mathrm{Bu}$ vakada chamfer bitim sınırı ile proksimal kenarlara doğru ilerleyerek proksimal boyutta rahat düzenlemeler yapmayı planlandı. Bu sayede kron boyunu uzatırken boy-en uyumu rahatıkla sağlandı. Kesici kenarların uzatılacağı vakalarda lingule doğru kesim yapılmaktadır. ${ }^{19}$ Kron boyu uzatma yapılacağı için kesici kenarlarda kesim yapıldı.

Porselen venerler iyi fonksiyon ve estetik sonuç elde edildiği, diş dokusu korunduğu için etkili bir tedavi alternatifidir. ${ }^{8,9,15-17}$ Konservatif tedavi seçeneğinin uygulanması restorasyonun uzun dönem başarısı için olumlu bir yaklaşımdır.

Porselen vener uygulaması açısından birçok teknik geliştirilmiştir. Presleme tekniği bunlardan biridir. ${ }^{13}$ Doğal dişlerin yanında yapılan veneerlerin doğal dişlerle uyumu saylamak için restorasyonda renklendirme yapılması gerekebilir. Restorasyonun üzerine yapılan boyama tekniği çoğunlukla kullanılan yöntemdir. ${ }^{13}$ Dişler ile restorasyonun uyumunu sağlamak için dişlerde beyazlatma yapılarak tek renk elde edilmeye çalışıldı. Restorasyonda presleme tekniği ile yapıldı ve boyama işlemine intiyaç kalmadı. Bu da restorasyonun uzun dönem renk uyumunu korunması için önemli bir yarar sağlayacaktır.

Bir restorasyonun kinik olarak değerlendirme kriterleri olan modifiye USPHS kullanılır. ${ }^{20}$ Porselen venerler de klinik olarak anatomik form, marjinal adaptasyon, renk uyumu ve sekonder çürük kriterlerinde değerlendirildi. Anatomik form, marjinal adaptasyon ve sekonder çürük alfa, renk uyumu bravo olarak skorlanmıştır.

Porselen venerler ile fonksiyon ve estetik sorunlar çözümlenmiş ve elde edilen sonuçlar 3 yıllık klinik takipte ideal olduğu gözlenmiştir. 


\section{KAYNAKLAR}

1. Yousefzadeh F, Shcherbatyy V, King GJ, Huang GJ, Liu Z. Cephalometric and electromyographic study of patients of East African ethnicity with and without anterior open bite Am J Orthod Dentofacial Orthop 2010;137:236-46.

2. Huang GJ, Greenlee GM. Stability of Anterior Open Bite Correction-An Assessment of the Evidence. Evidence-Based Orthodonticts, Blackwell Publishing; 2011 p:97-117. Ng CS, Wong WK, Hagg U. Orthodontic treatment of anterior open bite. Int $\mathrm{J}$ Paediatr Dent. 2008;18:78-83.

3. Parlani S, Patel S. Esthetic correction in open bite. Indian J Dent Res. 2011;22:580-2.

4. Seo YJ, Kim SJ, Munkhshur J, Chung KR, Ngan $\mathrm{P}, \mathrm{Kim} \mathrm{SH}$. Treatment and retention of relapsed anterior open-bite with low tongue posture and tongue-tie: A 10-year follow-up. Korean J Orthod. 2014;44:203-16.

5. Sadighpour L, Geramipanah F, Nikzad S. Fixed rehabilitation of an ACP PDI class III patient with amelogenesis imperfecta. $\mathrm{J}$ Prosthodont. 2009;18:64-70.

6. Sepolia S, Sepolia G, Kaur R, Gautam DK, Jindal V, Gupta SC. Visibility of gingiva - An important determinant for an esthetic smile. J Indian Soc Periodontol. 2014;18:488-92.

7. Aykent .F., Kara H.B, Özyılmaz Ö.Y Porselen Laminate Veneerler. Turkiye Klinikleri J Dental SciSpecial Topics 2011;2:14-21.

8. Gür E. Kesim B. Porselen laminate veneerler. CÜ Diş Hek Fak Derg 2004;7:72-79.

9. Şengün E, Çömlekoğlu M. E, Yılmaz G Lamina Venerlerin Final Rengine Etki Eden Faktörler $\mathrm{J}$ Dental Sci 2017;23:48-55.

10.Walls AWG., Steele JG. and Wassell RW.. Crowns and other extra-coronal restorations: Porcelain laminate veneers. British Dental Journal 2002; 193:73-82.

11.Zalkind M, Hochman N. Alternative method of conservative esthetic treatment for gingival recession. J Prosthet Dent. 1997;77:561-3.

12.Alani A, Maglad A, Nohl F. The prosthetic management of gingival aesthetics. $\mathrm{Br}$ Dent $\mathrm{J}$. 2011;210:63-9.

13. Furuse AY, Baratto SS, Spina DR, Correr GM, Cunha LF, Gonzaga CC..Planning extensive esthetic restorations for anterior teeth: use of waxed-up study casts and composite resin mockups. Gen Dent. 2016;64:6-9.

14.Dumfahrt $H$. Porcelain laminate veneers. A retrospective evaluation after 1 to 10 years of service: Part I--Clinical procedure. Int J Prosthodont. 1999;12:505-13.
15.D'Arcangelo C, De Angelis F, Vadini M, D'Amario M.Clinical evaluation on porcelain laminate veneers bonded with light-cured composite: results up to 7 years. Clin Oral Investig. 2012;16:1071-9.

16. Beier US, Kapferer I, Burtscher D, Dumfahrt H. Clinical performance of porcelain laminate veneers for up to 20 yearsInt J Prosthodont. 2012;25:79-85.

17.Bernardon JK, Ferrari P, Baratieri LN, Rauber GB Comparison of treatment time versus patient satisfaction in at-home and in-office tooth bleaching therapy. J Prosthet Dent. 2015; 114:826-30.

18. Garber DA ve Goldstein RE ve Feinman RA: Porcelain Laminate Veneers, Quintessence Publishing Co. Inc, Tokyo, 130, 1988.

19.Frese C, Schiller P, Staehle HJ, Wolff D. Recontouring teeth and closing diastemas with direct composite buildups: a 5-year follow-up. J Dent. 2013;41:979-85.

Yazışma Adresi:

Yrd.Doç.Dr. Ayşe KOÇAK BÜYÜKDERE

Kocaeli Üniversitesi

Diş Hekimliği Fakültesi Protetik Diş Tedavisi AD

Yuvacık Yerleşkesi

41190 Başiskele, Kocaeli, Türkiye

Tel : +90 5323165759

E-mail: a.buyukdere@yahoo.com

Faks : +90 2623442109 